\title{
TRICHINELLA SPIRALIS INFECTION PROTECTS AGAINST OVALBUMIN- INDUCED ALLERGIC BRONCHIAL ASTHMA IN A MURINE MODEL By
}

\author{
NORHAN B. SALLAM ${ }^{1}$, SANAA N. ANTONIOS ${ }^{1}$, NEMA A. SOLIMAN ${ }^{2}$ \\ AND DINA I. ELGENDY ${ }^{1 *}$
}

Department of Medical Parasitology ${ }^{1}$, and Department of Medical Biochemistry ${ }^{2}$, Faculty of Medicine, Tanta University, Egypt

( ${ }^{*}$ Correspondence: dina.elgendy@med.tanta.edu.eg)

\begin{abstract}
Allergic bronchial asthma is a long-lasting illness of the respiratory system characterized by chronic inflammation of the respiratory airways with abnormal Th2-type immune responses to specific allergens. The accumulation of scientific evidence supports the beneficial effects of some parasitic infections in animal models of allergic diseases. Thus, the aim of this work was to discover the influence of infection with $T$. spiralis on ovalbumin-induced acute allergic airway inflammation in mice and to investigate whether this effect is correlated to the infection dose or not. Therefore, the severity of respiratory airways inflammation, the leukocyte counts in the blood and BALF, immunohistochemistry of FOXP3 $3^{+} \mathrm{CD}^{+} \mathrm{T}$ cells and the levels of IL-6, IL13 , and IL-10 were assessed. In this experiment, 120 male laboratory bred mice were randomly divided into six groups: induced asthma, saline control, low dose preventive, high dose preventive, low dose therapeutic and high dose therapeutic groups. T. spiralis infection attenuated the intensity of pulmonary inflammation, decreased numbers of eosinophils in BALF and blood, reduced levels of IL-6 and IL-13 and elevated levels of IL-10 with a significant upregulation of FOXP ${ }^{+} \mathrm{CD}^{+} \mathrm{T}$ cells expression compared to the uninfected induced asthma group. The preventive groups showed the best results with no significant difference between effects of the low and the high doses. In conclusion, T. spiralis infection reduced Th2 type infammation and augmented regulatory immune response in ovalbumin-induced acute allergic airway inflammation with better preventive than therapeutic effects. Further investigations are needed to determine the minimal dose of infection that gives the best influence.
\end{abstract}

Key words: Trichinella spiralis; Helminthic therapy; Ovalbumin; Acute allergic airway inflammation; IL-6; IL-13; IL-10; FOXP3 ${ }^{+} \mathrm{CD}^{+}{ }^{+} \mathrm{T}$ cells

\section{Introduction}

Allergic bronchial asthma is a long-lasting illness of the respiratory system characterized by extensive, reversible, chronic inflammation of the respiratory airways with acute attacks of broncho-obstruction (Peters and Fritz, 2011). At least $10 \%$ of the world's population suffered from allergic diseases (Theofilopoulos, et al, 2017) and about 300 million people globally are suffering from bronchial asthma (Loukas et al, 2016). Besides, the incidence of bronchial asthma was increasing in the last 40 years particularly in the more developed countries (Bahadori et al, 2009; Ananden et al, 2010). The inflammatory reaction in allergic asthma was initiated by abnormal $\mathrm{T}$ helper 2 (Th2)-type immune responses to specific allergens leading to production of large amounts of cytokines including interleukin (IL-4), IL-5, IL-9, IL-
13 \& IL-14. Also, there was recruitment of inflammatory cells predominantly eosinophils, mast cells, basophils \& Th2 lymphocytes. Also, there were higher levels of allergen specific IgE (Di Lorenzo et al, 2009). Th2-type immune response was a common feature of allergic conditions, eosinophilic syndromes, and parasitosis (Fahy, 2015). Th2 lymphocytes were the main promoter and regulatory T-cells (Treg) the main suppressor of numerous characteristics of allergic inflammatory reaction in asthmatic patients (Lambrecht and Hammad, 2013).

The immune response to helminth infections was characterized by the release of certain regulatory cytokines that help in the reduction of the resulting inflammation and facilitate establishment of the chronic infection of helminth in the host. The effects may indirectly help the host by protecting him 
from autoimmune or atopic diseases (Cheng et al, 2018). The accumulation of scientific evidence supports the beneficial effects of some parasitic infections in animal models of allergic disorders (Chenery et al, 2016; Obieglo et al, 2018) and autoimmune diseases (El-Malky et al, 2011). The hopeful results from clinical studies supported the suppressor effect of some parasitic infections on these diseases (Fleming et al, 2011; Summers et al, 2005). Various studies in animal models of allergic asthma revealed that some parasites had the capacity to reduce the pathology of asthma by production of regulatory $\mathrm{T}$ cells and anti-inflammatory cytokines (Buck et al, 2014; Ebner et al, 2014; McSorley et al, 2014; Finlay et al, 2017). That's why the role of helminths and Helminthic therapy attract the attention of many authors worldwide (Zwiernik et al, 2019).

Trichinella spiralis (T. spiralis) is a distinctive luminal and tissue-dwelling parasitic helminth. It has the ability to manipulate the host immune response by shifting from Th1 to Th2/Treg response (Beiting et al, 2007; Guo et al, 2016). Several studies reported that $T$. spiralis infection, or the worm products had the capability to repress a set of autoimmune diseases in experimental animals including inflammatory bowel diseases (Yang et al, 2014), experimental autoimmune encephalomyelitis (Gruden-Movsesijan et $a l, 2010$ ), collagen induced arthritis (Eissa et al, 2016; Cheng et al, 2018), and type 1 diabetes (Saunders et al, 2007). Also, it could significantly alleviate allergic disorders $(\mathrm{Pa}-$ rk et al, 2011).

Little studies investigated the influence of $T$. spiralis infection on bronchial asthma. This work aimed to discover the possible influence of $T$. spiralis infection on ovalbumin-induced acute allergic airway inflammation in mice and to investigate whether it correlated to the infection dosage or not.

\section{Materials and Methods}

Parasite and Animals: T. spiralis strain (Istituto Superiore di Sanità code: ISS6158), maintained at Medical Parasitology Department, Tanta Faculty of Medicine, was used in per oral infection. 120 parasite-free male Swiss Albino mice (6-8 weeks old \& weighed 25-30gm supplied from Theodore Bilharz Research Institute (Giza) were used in this study.

Ethics statement: Animals were housed in appropriate cages. The care and use of the animals was according to the national and institutional guidelines. All the experiments were done in the Faculty of Medicine, Tanta University. The research ethics committee, Faculty of Medicine, Tanta University, approved the study and its approval code was $(33530 / 11 / 19)$.

Induction of $T$. spiralis infection: Three previously infected mice were sacrificed, skinned and eviscerated. After being grinded in meat grinder, the ground mice were put in an artificial gastric juice laboratory prepared in formed $1 \%$ pepsin (weight/vol.) and $1 \%$ concentrated HCL (volume/vol.) in $200 \mathrm{ml}$. warm tap water per mouse, and incubated at $37^{\circ} \mathrm{C}$ for 2 hours with persistent agitation by electric stirrer. The resultant fluid was filtered and suspended in a urine flask for about 30 minutes to allow larval sedimentation. The supernatant fluid was removed and the concentration of larvae in sediment was determined and adjusted to be 100 larvae/ 0.25 $\mathrm{ml}$. or 200 larvae $/ 0.25 \mathrm{ml}$. according to the required infection dose of every mouse and given orally (Dunn and Wright, 1985).

Induction and confirmation of acute allergic airway inflammation: Sensitization of the mice was done as follows; they received two intraperitoneal injections of $100 \mu \mathrm{g}$ of Ovalbumin (OVA) (Sigma-Aldrich, USA) in 200 $\mu \mathrm{l}$ of sterile normal saline adsorbed to $1 \mathrm{mg}$ of Aluminum hydroxide (alum) (Sigma, Aldrich, USA) as an adjuvant on days 0 and 7 followed by administration of two doses composed of $50 \mu \mathrm{g}$ of OVA in a total volume of $50 \mu \mathrm{l}$ of sterile normal saline per dose on days $14 \& 16$ by intranasal route (Aranzamend et al, 2012). The establishment confirmation of the acute allergic airway inflamma- 
tion model was settled by histopathological examination of the mice lung tissues as well as by the manifestations development including scratching of the head and nose, frequent sneezing followed OVA inhalation, development of abdominal muscle twitching and weight loss.

Experimental animals were randomly divided into six groups of 20 mice each: G1 (Induced asthma): was sensitized only. G2 (Saline control): received sterile normal saline by intra-peritoneal injection on day's $0 \& 7$, $\& 50 \mu 1$ sterile normal saline intranasal instillation on days $14 \& 16$. G3 (Low dose preventive): infected with $100 \mathrm{~T}$. spiralis muscle larvae/mouse and their sensitization started on the $28^{\text {th }}$ day post infection (P.I.). G4 (High dose preventive): infected with 200 T. spiralis muscle larvae/mouse and the sensitization started on the $28^{\text {th }}$ day P.I. G5 (Low dose therapeutic): infected with $100 T$. spiralis muscle larvae/mouse and the sensitization started on the $10^{\text {th }}$ day P.I. G6 (High dose therapeutic): infected with 200 T. spiralis muscle larvae/mouse and the sensitization started on the $10^{\text {th }}$ day P.I.

Mice were sacrificed on the $18^{\text {th }}$ day of sensitization using the approved methods of euthanasia (Close et al, 1997) and were submitted to the following procedures:

Histopathological study of lung tissues: The right lung of each mouse was inflated with $0.5 \mathrm{~mL}$ paraformaldehyde, $10 \%$ in phosphate buffer saline (PBS) $(0.4 \mathrm{~m} \mathrm{NaCl} \&$ $10 \mathrm{mM}$ NaPO4) prior to removal. They were fixed in $10 \%$ phosphate-buffered formalin, dehydrated, embedded in paraffin, sectioned at $3 \mu \mathrm{m}$ thickness, and then stained with hematoxylin and eosin (H\&E). Lung sections were sliced and mounted onto clean glass slides. Three thin cut sections per sample were done. Slides were examined by a blinded pathologist using a light microscope to determine the degree of histopathological changes. The pathological lesions in form of (peribronchiolar inflammation, perivascular inflammation, hypertrophy and hyperplasia of goblet cells) were blindly scored using a semi-quantitative scoring system ranging from absent (no inflammatory cells), mild (a circle of inflammatory cells of 1 cell layer depth), moderate (a circle of inflammatory cells of 2-4 cells depth) to marked inflammation (a circle of inflammatory cells of more than 4 cells depth) (Trujillo-Vargas, 2005). The histopathological parameters were evaluated in 5 low-power fields $(\times 10)$ per section, and the average score was determined.

Immunohistochemical study to assess the FOXP $3{ }^{+} \mathrm{CD} 4{ }^{+} \mathrm{T}$ cells expression in lung tissues: Paraffin-embedded sections were submitted to deparaffinization in xylene, washed in PBS ( $\mathrm{pH} 7.4)$, rehydration in a graded series of ethanol solutions, and microwave heating for $15 \mathrm{~min}$ in citric buffer ( $\mathrm{pH}$ 6.0) for antigen retrieval. Next, endogenous peroxidase activity was blocked by addition of $3 \%$ hydrogen peroxide and incubation for 10 min. Blocking with normal serum (Invitrogen, Carlsbad, CA) was done followed 30 min later by addition of the primary Goat Anti-FOXP3 (Mouse) Antibody (Catalog No \#OAEB00854, Aviva Systems Biology, USA) and incubation overnight at $4^{\circ} \mathrm{C}$. Slides washing with PBS was repeated three times, each for $5 \mathrm{~min}$. After that, the biotinlabeled secondary antibody and the streptavidinbiotin complex were added, each for $1 \mathrm{hr}$ incubation at room temperature. Slides were dipped in PBS, followed by immersion for $10 \mathrm{~min}$ in 3, 3'-diaminobenzidine-tetrahydrochlorhydrate (DAB) (Merck, Darmstadt, Germany) solution $(0.4 \mathrm{mg} / \mathrm{mL}$ with $0.003 \%$ hydrogen peroxide). Microscopic monitoring of reaction was done and terminated by adding distilled water. The counter-staining with hematoxylin, dehydration and coverslipping of slides were done. Immunoreactivity of $\mathrm{FOXP} 3^{+} \mathrm{CD} 4^{+} \mathrm{T}$ cells appeared as brown staining of variable degrees of intensity in cytoplasm and/or nucleus of cells. For negative control, normal mouse serum was used instead of the primary antibody and human normal tonsil tissue was used as a positive control.

For the assessment of $\mathrm{FOXP} 3^{+} \mathrm{CD} 4^{+} \mathrm{T}$ cells 
expression in the lung tissues, examination of 10 high-power fields $(\times 400)$ in each slide by light microscope was done, and the average immunohistochemical score (IHS) was determined. First staining intensity score: $(0$ = negative, 1 = weak, 2 = moderate, $\& 3=$ strong) and the quantity score (percentage of stained cells) $(0=$ no immunostaining; $1=$ $1-10 \%$ of cells are positive; $2=11-50 \%$ are positive; $3=51-80 \%$ are positive; and $4=\geq$ $81 \%$ of positive) cells were determined. The IHS ranged from 0 to 12 and calculated by means of multiplication of staining intensity score by the quantity score. Negative, weak, moderate or strong immunoractivity corresponded to 0 , (1-4), (5-8), and (9-12) IHS scores respectively (Gou et al, 2011).

Examination of blood samples and Bronchoalveolar Lavage fluid (BALF): Collection of $20 \mu \mathrm{l}$ blood sample from the bleeding surface at distal part of each mouse tail was done using a pipette containing EDTA anticoagulant. Besides, to collect BALF, ligation of the main stem bronchus of the left lung was done, followed by exposure and cannulation of the trachea through a minor slit inferior to its proximal end using a $1 \mathrm{ml}$ syringe and 23-gauge needle sheathed with polyethylene tubing. Bronchoalveolar washing was done by infusing 1-ml aliquots of sterile saline, followed by gentle massage of the thorax and careful aspiration of the fluid. This procedure was done three times. The entire collected specimen was assembled in a centrifuge tube and rapidly, within $1 \mathrm{hr}$, centrifugation of $1 \mathrm{ml}$ of the fluid at $400 \times \mathrm{g}$, $4^{\circ} \mathrm{C}$ for $10 \mathrm{~min}$. was done. After elimination of the supernatant, sediment was resuspended in $200 \mu \mathrm{l}$ saline and used for cell counting. Leukocytes in blood and BALF were quantified using a hemocytometer to determine total leukocyte counts followed by performance of differential leukocyte counts on Giemsa and Wright's stained slides. Two hundred cells were counted per slide.

ELISA measurement of IL-6, IL-13 \& IL10 in lung tissue homogenates: A part weighed $100 \mathrm{mg}$ of each lung was washed with
PBS, dissected, homogenized in $1 \mathrm{ml}$ of PBS and stored overnight at $-20^{\circ} \mathrm{C}$. The homogenates were submitted two times to freezing and thawing to breakdown the cell membranes followed by centrifugation for $20 \mathrm{~min}$. at $12,000 \times \mathrm{g}, 2-8^{\circ} \mathrm{C}$. The supernatant fluid was collected and kept at $-80^{\circ} \mathrm{C}$. Centrifugation of the samples was done again after thawing before the examination using ELISA kits for quantitative detection of mouse IL-6 (Cata$\log$ No \#M6000B, R\&D Systems Inc, Minneapolis, MN, USA), IL-13 (Catalog No \#887137-22, eBioscience, San Diego, CA, USA) \& IL-10 (Catalog No \#OKBB00194, Aviva Systems Biology, USA) following the manufacturer's protocol.

Statistical analysis: Data were expressed as mean \pm standard deviation, analyzed for significance $(\mathrm{P}<0.05)$ by statistical analysis of variance (ANOVA) and the Tukey test for multiple comparisons to determine statistical differences between more than two groups. Student's $t$-test was used for comparison between two groups. Monte Carlo exact test for chi-square was utilized for analysis of histopathological and immunohistochemical scores. Analyses were done by software for windows, SPSS version 20.

\section{Results}

Histopathological and immunohistochemical results: To determine whether $T$. spiralis infection could prevent and/or reduce features of lung pathology associated with allergic airway inflammation in an OVA-alum acute allergic airway inflammation mouse model, existence of related histopathological parameters including peribronchiolar, perivascular inflammation and hypertrophy and hyperplasia of goblet cells were examined in H\&E stained lung sections. Typically inflammatory cell infiltration of lungs, which was characteristic to asthma acute phase, was exacerbated in induced asthma group with marked peribronchial and perivascular inflammatory cell infiltration and adjacent blood vessels congestion (Fig. 1A). In contrast, saline control ones did not show any signs of inflammation or cell infiltration (Fig. 1B). Sem- 
iquantitative analysis of pathological features in low \& high dose preventive group showed significantly reduced peribronchiolar \& perivascular inflammatory cell infiltration of lungs with mild score (Fig. 1C, \& D). Decreased inflammation was in low $\&$ high dose therapeutic groups as compared to induce asthma group with moderate inflammatory cell infiltration (Tab. 1; Fig. 1E, \& F).

Immunohistochemical score of $\mathrm{FOXP}^{+}$ $\mathrm{CD} 4^{+} \mathrm{T}$ cells expression in lung tissues showed upregulation in T. spiralis infected mice in comparison with induced asthma group. It was strong to moderate in low \& high dose preventive mice (Fig. 2C, \& D) and weak to moderate in low \& high dose therapeutic groups (Figs. 2E, \& F), but weak to negative in induced asthma group (Tab. 2; Fig. 2A).

Leukocyte counts in blood \& BALF: Blood samples and the BALF of induced asthma group presented elevated levels of total leukocyte, eosinophil counts in comparison with the saline control group. Similarly, counts of neutrophils, monocytes and lymphocytes in the blood of induced asthma group were significantly higher than those of the saline control group. Mice in low and high dose preventive groups had significantly decreased cell counts relative to cell counts of induced asthma group. Reduction in cell counts in preventive groups was significantly higher than the therapeutic groups, without significant difference between low dose \& high dose preventive groups. Also, difference was non-significant between low dose \& high dose therapeutic groups except for blood eosinophil counts were significantly lower in low dose therapeutic group compared to high dose therapeutic one (Tabs. $3 \& 4$ ).

Assay of cytokines levels in lung tissue homogenates: Trying to find out the underlying mechanisms of the possible preventive or therapeutic effects of $T$. spiralis infection on acute allergic airway inflammation, this study investigated some key cytokines in the pathogenesis of both allergic asthma and $T$. spiralis infection including Th1 proinflammatory cytokine (IL-6), Th2 cytokine (IL13) and regulatory cytokine (IL-10) in lung tissue homogenates. IL-6 \& IL-13 levels were significantly elevated in induced asthma group compared with saline control. But, there was a significant decrease in both cytokines levels in all T. spiralis infected ones. This reduction was significantly higher in the preventive groups relative to the therapeutic groups. In contrast, a significant upregulation in IL-10 levels was observed in all the infected groups compared with the induced asthma group. The low dose preventive group showed the lowest levels of the proinflammatory cytokines IL-6 and IL13 and the highest level of the regulatory cytokine IL-10 in comparison with the other T. spiralis infected groups (Tab. 5).

Table 1: Semiquantitative analysis of histopathological changes in the lung tissues of groups $(\mathrm{n}=10)$

\begin{tabular}{|c|c|c|c|c|c|c|c|c|c|c|c|c|}
\hline \multirow{2}{*}{$\begin{array}{l}\text { Examined } \\
\text { mice }\end{array}$} & \multicolumn{4}{|c|}{ Peribronchiolar inflammation } & \multicolumn{4}{|c|}{ Perivascular inflammation } & \multicolumn{4}{|c|}{ Hypertrophy and hyperplasia of goblet cells } \\
\hline & Absent & Mild & Moderate & Marked & Absent & Mild & Moderate & Marked & Absent & Mild & Moderate & Marked \\
\hline G1 & 0 & 0 & 1 & 9 & 0 & 0 & 2 & 8 & 0 & 0 & 2 & 8 \\
\hline G2 & 10 & 0 & 0 & 0 & 10 & 0 & 0 & 0 & 10 & 0 & 0 & 0 \\
\hline G3 & 0 & 8 & 2 & 0 & 1 & 7 & 1 & 1 & 2 & 6 & 2 & 0 \\
\hline G4 & 0 & 7 & 3 & 0 & 0 & 7 & 2 & 1 & 2 & 5 & 3 & 0 \\
\hline G5 & 0 & 2 & 7 & 1 & 0 & 3 & 5 & 2 & 0 & 2 & 8 & 0 \\
\hline G6 & 0 & 1 & 8 & 1 & 0 & 3 & 4 & 3 & 0 & 1 & 9 & 0 \\
\hline $\mathrm{X}^{2}$ & \multicolumn{4}{|c|}{108.286} & \multicolumn{4}{|c|}{82.917} & \multicolumn{4}{|c|}{103.073} \\
\hline$P$ value & \multicolumn{4}{|c|}{$0.001^{*}$} & \multicolumn{4}{|c|}{$0.001^{*}$} & \multicolumn{4}{|c|}{$0.001 *$} \\
\hline
\end{tabular}

* $P<0.05$, Chi-square (X2) test of significance compared proportions between qualitative parameters Table 2: Immunohistochemical score of FOXP $3^{+} \mathrm{CD} 4^{+} \mathrm{T}$ cells expression in lung tissues of groups $(\mathrm{n}=10)$

\begin{tabular}{|c|c|c|c|c|}
\hline \multirow{2}{*}{ Number of examined mice } & \multicolumn{4}{|c|}{$\mathrm{CD}^{+} \mathrm{FOXP}^{+} \mathrm{T}$ cells Immunohistochemical Score } \\
\cline { 2 - 5 } & Negative & Weak & Moderate & Strong \\
\hline $\mathrm{G} 1$ & 7 & 3 & 0 & 0 \\
\hline $\mathrm{G} 2$ & 10 & 0 & 0 & 0 \\
\hline $\mathrm{G} 3$ & 0 & 0 & 2 & 7 \\
\hline $\mathrm{G} 4$ & 0 & 0 & 3 & 0 \\
\hline $\mathrm{G} 5$ & 0 & 1 & 9 & 0 \\
\hline $\mathrm{G} 6$ & 0 & 2 & 8 & \\
\hline $\mathrm{X} 2$ & \multicolumn{5}{|c|}{58.001} \\
\hline value & \multicolumn{5}{|l}{$0.001^{*}$} \\
\hline
\end{tabular}


Table 3: Total and differential leukocyte counts in blood samples of groups $(\mathrm{n}=10)$

\begin{tabular}{|c|c|c|c|c|c|c|}
\hline (cells /microliter) & G1 & $\mathrm{G} 2$ & G3 & G4 & G5 & G6 \\
\hline $\begin{array}{l}\text { Total leukocyte } \\
\text { count }(\text { Mean } \pm \text { SD) }\end{array}$ & $17790 \pm 1112.65$ & $3790 \pm 617.62$ & $12790 \pm 733.48$ & $13470 \pm 875.79$ & $14762 \pm 524.61$ & $14820 \pm 488.11$ \\
\hline F test & \multicolumn{6}{|c|}{120.985} \\
\hline$P 1$ & & $0.001 *$ & $0.001 *$ & $0.001 *$ & $0.001 *$ & $0.001 *$ \\
\hline$P 2$ & & & $0.001 *$ & $0.001 *$ & $0.001 *$ & $0.001 *$ \\
\hline$P 3$ & & & & 0.280 & $0.004 *$ & $0.003 *$ \\
\hline$P 4$ & & & & & $0.046^{*}$ & $0.038^{*}$ \\
\hline$P 5$ & & & & & & 0.926 \\
\hline Eosinophils & $8760 \pm 827.16$ & $736 \pm 177.29$ & $3732 \pm 861.84$ & $4218 \pm 401.15$ & $6968 \pm 536.58$ & $7974 \pm 582.39$ \\
\hline F test & \multicolumn{6}{|c|}{123.679} \\
\hline$P 1$ & & $0.001 *$ & $0.001 *$ & $0.001 *$ & $0.001 *$ & 0.053 \\
\hline$P 2$ & & & $0.001 *$ & $0.001 *$ & $0.001 *$ & $0.001 *$ \\
\hline$P 3$ & & & & 0.221 & $0.001 *$ & $0.001 *$ \\
\hline$P 4$ & & & & & $0.001 *$ & $0.001 *$ \\
\hline$P 5$ & & & & & & $0.016^{*}$ \\
\hline Monocytes & $2724 \pm 452.36$ & $62 \pm 24.88$ & $530 \pm 111.36$ & $602 \pm 77.91$ & $2574 \pm 477.89$ & $2602 \pm 440.87$ \\
\hline F test & \multicolumn{6}{|c|}{71.277} \\
\hline$P 1$ & & $0.001^{*}$ & $0.001 *$ & $0.001 *$ & 0.477 & 0.562 \\
\hline$P 2$ & & & $0.034 *$ & $0.016^{*}$ & $0.001^{*}$ & $0.001 *$ \\
\hline$P 3$ & & & & 0.732 & $0.001 *$ & $0.001 *$ \\
\hline$P 4$ & & & & & $0.001 *$ & $0.001 *$ \\
\hline$P 5$ & & & & & & 0.894 \\
\hline $\begin{array}{ll}\begin{array}{l}\text { Segmented neutro- } \\
\text { phils }\end{array} & \\
\end{array}$ & $4140 \pm 288.10$ & $1530 \pm 269.81$ & $2260 \pm 207.36$ & $2320 \pm 189.21$ & $3140 \pm 151.66$ & $3304 \pm 161.96$ \\
\hline F test & \multicolumn{6}{|c|}{90.862} \\
\hline$P 1$ & & $0.001 *$ & $0.001 *$ & $0.001 *$ & $0.001 *$ & $0.001 *$ \\
\hline$P 2$ & & & $0.001 *$ & $0.001 *$ & $0.001 *$ & $0.001 *$ \\
\hline$P 3$ & & & & 0.667 & $0.001 *$ & $0.001 *$ \\
\hline$P 4$ & & & & & $0.001^{*}$ & $0.001 *$ \\
\hline$P 5$ & & & & & & 0.245 \\
\hline Lymphocytes & $3846 \pm 55.50$ & $1276 \pm 193.98$ & $2306 \pm 148.93$ & $2392 \pm 98.34$ & $2680 \pm 216.68$ & $2792 \pm 116.92$ \\
\hline F test & \multicolumn{6}{|c|}{155.998} \\
\hline$P 1$ & & $0.001^{*}$ & $0.001 *$ & $0.001 *$ & $0.001 *$ & $0.001 *$ \\
\hline$P 2$ & & & $0.001 *$ & $0.001 *$ & $0.001 *$ & $0.001 *$ \\
\hline$P 3$ & & & & 0.370 & $0.001 *$ & $0.001 *$ \\
\hline$P 4$ & & & & & $0.005^{*}$ & $0.001 *$ \\
\hline$P 5$ & & & & & & 0.246 \\
\hline
\end{tabular}

* $P<0$.05. P1: Comparison with G1, P2: Comparison with G2, P3: Comparison with G3, P4: Comparison with G4 \& P5: Comparison with G5

Table 4: Total leukocyte count and eosinophils count in bronchoalveolar lavage fluid $(\mathrm{n}=10)$

\begin{tabular}{|c|c|c|c|c|c|c|}
\hline (cells / microliter) & G1 & G2 & G3 & G4 & G5 & G6 \\
\hline $\begin{array}{l}\text { Total leukocyte } \\
\text { count }(\text { Mean } \pm \text { SD) }\end{array}$ & $284 \pm 14.82$ & $29 \pm 6.44$ & $59.8 \pm 6.98$ & $64 \pm 6.89$ & $107.2 \pm 4.97$ & $113 \pm 4.90$ \\
\hline F test & \multicolumn{6}{|c|}{613.280} \\
\hline$P 1$ & & $0.001 *$ & $0.001 *$ & $0.001 *$ & $0.001 *$ & $0.001 *$ \\
\hline$P 2$ & & & $0.001^{*}$ & $0.001 *$ & $0.001^{*}$ & $0.001^{*}$ \\
\hline$P 3$ & & & & 0.427 & $0.001 *$ & $0.001^{*}$ \\
\hline$P 4$ & & & & & $0.001^{*}$ & $0.001 *$ \\
\hline$P 5$ & & & & & & 0.276 \\
\hline Eosinophils & $67 \pm 11.90$ & $1.4 \pm 0.39$ & $10.6 \pm 1.14$ & $11.2 \pm 1.30$ & $24.4 \pm 3.58$ & $26 \pm 3.39$ \\
\hline $\mathrm{F}$ test & \multicolumn{6}{|c|}{95.428} \\
\hline$P 1$ & & $0.001 *$ & $0.001 *$ & $0.001 *$ & $0.001 *$ & $0.001 *$ \\
\hline$P 2$ & & & $0.012^{*}$ & $0.008^{*}$ & $0.001^{*}$ & $0.001^{*}$ \\
\hline$P 3$ & & & & 0.860 & $0.001^{*}$ & $0.001 *$ \\
\hline$P 4$ & & & & & $0.001^{*}$ & $0.001 *$ \\
\hline$P 5$ & & & & & & 0.639 \\
\hline
\end{tabular}

* $P<0$ 05. P1: Comparison with G1, P2: Comparison with G2, P3: Comparison with G3, P4: Comparison with G4 \& P5: Comparison with G5 
Table 5: Cytokine levels in lung tissue homogenates $(\mathrm{n}=10)$

\begin{tabular}{|c|c|c|c|c|c|c|}
\hline & G1 & G2 & G3 & G4 & G5 & G6 \\
\hline $\begin{array}{l}\mathrm{IL}-6(\mathrm{pg} / \mathrm{mg} \text { protein }) \\
(\text { Mean } \pm \mathrm{SD})\end{array}$ & $153.4 \pm 4.04$ & $101.6 \pm 4.62$ & $105.8 \pm 3.11$ & $110.6 \pm 3.91$ & $136.8 \pm 2.77$ & $138.6 \pm 1.52$ \\
\hline F test & \multicolumn{6}{|c|}{186.166} \\
\hline$P 1$ & & $0.001 *$ & $0.001 *$ & $0.001 *$ & $0.001 *$ & $0.001 *$ \\
\hline$P 2$ & & & 0.068 & $0.001 *$ & $0.001 *$ & $0.001 *$ \\
\hline$P 3$ & & & & $0.039 *$ & $0.001 *$ & $0.001 *$ \\
\hline$P 4$ & & & & & $0.001 *$ & $0.001 *$ \\
\hline$P 5$ & & & & & & 0.421 \\
\hline $\mathrm{IL}-13(\mathrm{pg} / \mathrm{mg}$ protein $)$ & $606.2 \pm 76.59$ & $108.8 \pm 7.36$ & $174.6 \pm 29.31$ & $185.2 \pm 25.20$ & $355.8 \pm 54.06$ & $368 \pm 56.28$ \\
\hline F test & \multicolumn{6}{|c|}{74.173} \\
\hline$P 1$ & & $0.001 *$ & $0.001 *$ & $0.001 *$ & $0.001 *$ & $0.001 *$ \\
\hline$P 2$ & & & $0.038 *$ & $0.018^{*}$ & $0.001 *$ & $0.001 *$ \\
\hline$P 3$ & & & & 0.727 & $0.001 *$ & $0.001 *$ \\
\hline$P 4$ & & & & & $0.001 *$ & $0.001 *$ \\
\hline$P 5$ & & & & & & 0.688 \\
\hline $\mathrm{IL}-10(\mathrm{pg} / \mathrm{mg}$ protein $)$ & $162.6 \pm 7.27$ & $114.4 \pm 5.37$ & $588.2 \pm 9.63$ & $567 \pm 17.84$ & $268.8 \pm 14.75$ & $242 \pm 26.32$ \\
\hline F test & \multicolumn{6}{|c|}{891.879} \\
\hline$P 1$ & & $0.001 *$ & $0.001 *$ & $0.001 *$ & $0.001 *$ & $0.001 *$ \\
\hline$P 2$ & & & $0.001 *$ & $0.001 *$ & $0.001 *$ & $0.001 *$ \\
\hline$P 3$ & & & & $0.037 *$ & $0.001 *$ & $0.001 *$ \\
\hline$P 4$ & & & & & $0.001 *$ & $0.001 *$ \\
\hline$P 5$ & & & & & & $0.011 *$ \\
\hline
\end{tabular}

* $P<0.05$. P1: Comparison with G1, P2: Comparison with G2, P3: Comparison with G3, P4: Comparison with G4 \& P5: Comparison with G5

\section{Discussion}

The accumulating data about the substantial role of helminths in modulation of the host immune response has encouraged investigation into the medical applications of helminths (Dunne and Cooke, 2005; Zwiernik et al, 2019). T. spiralis infection modulates the host immune response by different me-chanisms including down regulation of Th1 and Th17-associated cytokines, upgrading of Th2-associated cytokines, promotion of Treg cell-associated cytokines, and the stimulation of various regulatory cells (Sofronic-Milosavljevic et al, 2015). These immune-modulating effects of $T$. spiralis were explo-red in the treatment of numerous immunological disorders. For example, experimental autoimmune encephalomyelitis, inflammatory bowel disease and collageninduced arthritis (Gruden-Movsesijan et al, 2010; Yang et al, 2014; Cheng et al, 2018).

The role of helminths in damping allergic diseases was widely investigated (Mangan et al, 2006; Smits et al, 2007; Dittrich et al, 2008). Here in, this study looked at the effects of T. spiralis infection in alleviation of the pathological features of ovalbumin induced mouse model of acute allergic airway inflammation. Furthermore, it aimed to de- termine whether this modulation could be affected by reducing the infection dosage or not. The marked peribronchitis and perivasculitis, the upregulation in the total leukocyte counts and eosinophil counts in the blood and BALF together with the elevated Th2cytokine IL-13 in the lung tissue homogenates of the induced asthma group indicate that the induction of allergic airway inflammation model was efficient. These findings agreed with Marinho et al. (2016) who described matching results.

The histopathological score of lung tissue inflammation in $T$. spiralis infected groups was significantly reduced than non-infected induced asthma group. Similar reduction in the inflammatory reaction was also reported in models of arthritis and colitis treated with T. spiralis infection (Cheng et al, 2018; Ashour et al, 2014) signified a direct effect of $T$. spiralis infection in reduction of the inflammatory response. Also, the results of cell counts in the blood and BALF were supportive to histopathological findings as there was significant reductions in the total leukocyte counts, eosinophil counts, neutrophil counts in preventive groups compared to induced asthma group. In this context, it was well established that the eosinophils are 
the chief cells in the response to allergens. Additionally, they are the key inflammatory cells implicated in the pathophysiology of asthma whether allergic and nonallergic (Lambrecht and Hammad, 2014; Brusselle et al, 2013). They release proinflammatory cytokines that aggravate the associated allergen induced inflammation (Erpenbeck et al, 2003; Shamri et al, 2010). That's why; the reduction in the intensity of pulmonary inflammation could be attributed to the reduced eosinophils recruitment. Besides, the reduction in neutrophils influx in the lung tissues following $T$. spiralis infection could be explained by the ability of the parasite to secrete a $45 \mathrm{kDa}$ glycoptotein capable of hindering neutrophils migrations (Bruschi et al, 2000).

$\mathrm{CD} 4{ }^{+} \mathrm{CD} 25^{+}$regulatory $\mathrm{T}$ cells represented around $5-10 \%$ of $\mathrm{CD}^{+} \mathrm{T}$ cells in healthy mice. Their regulatory function necessitates the expression of the forkhead-winged helix transcription factor gene (FOXP3) (Fontenot et al, 2003; Khattri et al, 2003). They contributed in the downregulation of Th1 mediated inflammation and Th2-mediated disorders (Tang and Bluestone, 2008). A growing body of evidence supports the existence of alterations or impairments in either the count or the function of Treg cells in allergic individuals relative to healthy controls (Ling et al, 2004; Shi et al, 2004). During T. spiralis infection, there is an increase in the counts and the activity of these populations of cells. Moreover, they have an active role in the immune response throughout the muscular phase of trichinellosis (Beiting et al, 2007). In this work, immunohistochemical staining of the lung tissue sections showed the absence or the presence of a very few number of FOXP $3{ }^{+} \mathrm{CD} 4^{+} \mathrm{T}$ cells within inflammatory cell infiltrate in induced asthma group. By contrast, the expression was strong to moderate in the preventive groups and weak to moderate in the therapeutic groups. These results coincide with the in vitro results of Aranzamendi et al. (2012) which showed a significant effect of $T$. spiralis extracts in increasing the expansion of functional Treg cells. Furthermore, Eissa et al. (2016) detected similar effects of adminstration of $T$. spiralis antigen in the treatment of induced arthritis and Ashour et al. (2014) reported same effects of $T$. spiralis infection on FOX$\mathrm{P} 3{ }^{+} \mathrm{CD} 4^{+} \mathrm{T}$ cells expression in induced colitis model.

In the present study, the detected changes in the cytokines profile in the lung tissue homogenates included upregulation of regulatory arm of the immune response and inhibition of both Th1 and Th2 immune responses in the infected groups. These findings are confirmative to the findings of other studies that have shown similar effects of $T$. spiralis infection on the immune response (Beiting et al, 2007; Cho et al, 2012; Ilic et al, 2012). Other investigators showed that IL-10 has an inhibitory effect on the production of proinflammatory cytokines including both Th1 and Th2 related cytokines. Besides, it interferes with eosinophils activation (Hawrylowicz and O'Garra, 2005). This could explain the decrease in the levels of IL-6 and IL-13 in lung tissue homogenates and the reduction in eosinophil counts in the BALF in the infected groups. Additionally, this suggests a correlation between the reduction of the intensity of inflammation in the lungs and the augmentation in the levels of the anti-inflammatory cytokine IL-10. These results go hand in hand with those of the expression of $\mathrm{FOXP} 3{ }^{+} \mathrm{CD}^{+}{ }^{+}$Tcells within the lung tissues as they proved to have a major role in the production of IL-10 (Asseman et al, 1999; Annacker et al, 2001; Suri-Payer and Cantor, 2001; Klein et al, 2003).

Of interest, this study examined the effect of two different doses of $T$. spiralis infection 100 or 200 muscle larvae/ mouse 28 days or 10 days before induction of asthma. The results showed a protective effect of either dose at both time points on induced asthma. However, the best results were those of the preventive groups with non-significant difference between the effect of low and high doses of infection. This agreed with Aranza- 
mendi et al. (2012) who concluded that the degree of the protection intensified with the progression of the course of infection reaching the best effects in the chronic muscle phase. The time needed for the muscle larval stage of $T$. spiralis to develop and induce proliferation of Treg cells was the main factor to determine the protective effect that he$1 p$ in the relief of allergic airway inflammation (Fabre et al, 2009).

\section{Conclusion}

The pulmonary inflammatory response in an ovalbumin-induced acute allergic airway inflammation murine model was significantly alleviated by associated infection with $T$. spiralis. Activation of $\mathrm{FOXP} 3^{+} \mathrm{CD} 4^{+} \mathrm{T}$ cells and the release of the anti-inflammatory cytokine IL-10 were potential mechanisms included in this effect. These protective effects were not dependent on the infection dose but affected by the period of the preexistence of $T$. spiralis infection before onset of ovalbumin sensitization. Studies to determine the smallest dose of infection that produces the best effects and to understand the mechanistic role of $\mathrm{FOXP} 3^{+} \mathrm{CD} 4^{+} \mathrm{T}$ cells in controling allergic airway inflammation are ongoing and will be published in due time.

\section{Acknowledgement}

The authors would like to thank Prof. Dr. Safinaz H. Elshorbagy, Professor of Pathology, Faculty of Medicine, Tanta University, for her kind assistance in performing and reviewing the histopathological and immunohistochemichal part of the study.

Conflict of interest: The authors declared that they neither have any interest nor received fund.

\section{References}

Anandan, C, Nurmatov, U, Van Schayck, OC P, Sheikh, A, 2010: Is the prevalence of asthma declining? Systematic review of epidemiological studies. Allergy 65, 2:152-67.

Annacker, O, Pimenta-Araujo, R, Burlen-Defranoux, O, Barbosa, TC, Cumano, A, Bandeira, A, 2001: $\mathrm{CD} 25+\mathrm{CD} 4+\mathrm{T}$ cells regulate the expansion of peripheral CD4 T cells through production of IL-10. J. Immunol. 166, 5:3008-18.
Aranzamendi, C, Fransen, F, Langelaar, M, Franssen, F, Van Der, LEYP, et al, 2012: Trichinella spiralis-secreted products modulate DC functionality and expand regulatory $\mathrm{T}$ cells in vitro. Parasit. Immunol. 34, 4:210-23.

Ashour, DS, Othman, AA, Shareef, MM, Gaballah, HH, Mayah, WW, 2014: Interactions between Trichinella spiralis infection and induced colitis in mice. J. Helminthol. 88, 2:210-23.

Asseman, C, Mauze, S, Leach, MW, Coffman, RL, Powrie, F, 1999: An essential role for interleukin 10 in the function of regulatory $\mathrm{T}$ cells that inhibit intestinal inflammation. J. Exp. Med. 190, 7:995-1004.

Bahadori, K, Doyle-Waters, MM, Marra, C, Lynd, L, Alasaly, K, Swiston, J, FitzGerald, J M, 2009: Economic burden of asthma: a systematic review. BMC Pulm Med. 9, 1:24-33.

Beiting, DP, Gagliardo, LF, Hesse, M, Bliss, S $\mathrm{K}$, Meskill, D, et al, 2007: Coordinated control of immunity to muscle stage Trichinella spiralis by IL-10, regulatory T cells, and TGF- $\beta$. J. Immunol. 178, 2:1039-47.

Bruschi, F, Carulli, G, Azzarà, A, Homan, W, Minnucci, S, et al, 2000: Inhibitory effects of human neutrophil functions by the $45-\mathrm{kD}$ glycoprotein derived from the parasitic nematode Trichinella spiralis. Int. Arch. Aller. Immunol. 122, 1:58-65.

Brusselle, GG, Maes, T, Bracke, KR, 2013: Eosinophils in the spotlight: Eosinophilic airway inflammation in non-allergic asthma. Nat. Med. 19, 8:977-9.

Buck, AH, Coakley, G, Simbari, F, McSorley, HJ, Quintana, JF, et al, 2014: Therapeutic potential of larval excretory/secretory proteins of the pig whipworm Trichuris suis in allergic disease. Allergy 69:1489-97.

Chenery, AL, Antignano, F, Burrows, K, Scheer, S, Perona-Wright, G, et al, 2016: Lowdose intestinal Trichuris muris infection alters the lung immune microenvironment and can suppress allergic airway inflammation. Infect. Imm un. 84, 2:491-501.

Cheng, Y, Zhu, X, Wang, X, Zhuang, Q, Huyan, $X$, et al, 2018: Trichinella spiralis infection Mitigates collagen-induced arthritis via Programmed Death 1-Mediated immunomodulation. Front Immunol. 9:1566-70.

Cho, MK, Park, MK, Kang, SA, Choi, SH, Ahn, SC, et al, 2012: Trichinella spiralis infection suppressed gut inflammation with CD4+ 
CD25+Foxp3+ T cell recruitment. Korean J. Parasitol. 50, 4: 385.

Close, MB, Banister, K, Baumans, V, Bernoth, EM, Bromage, N, et al, 1996: Recommendations for euthanasia of experimental animals: Part. Lab Anim. 30:293-316.

Di Lorenzo, G, Mansueto, P, Pacor, ML, Rizzo, M, Castello, F, et al, 2009: Evaluation of serum s-IgE/total IgE ratio in predicting clinical response to allergen-specific immunotherapy. J. Aller. Clin. Immunol. 123, 5:1103-10.

Dittrich, AM, Erbacher, A, Specht, S, Diesner, F, Krokowski, M, et al, 2008: Helminth infection with Litomosoides sigmodontis induces regulatory $\mathrm{T}$ cells and inhibits allergic sensitization, airway inflammation, and hyper-reactivity in a murine asthma model. J. Immunol.180, 3: 1792-9.

Dunn, IJ, Wright, KA, 1985: Cell injury caused by Trichinella spiralis in the mucosal epithelium of B10A mice. J. Parasitol. 71, 6:757-66.

Dunne, DW, Cooke, A, 2005: A worm's eye view of the immune system: Consequences for evolution of human autoimmune disease. Nat. Rev. Immunol. 5, 5:420-6.

Eissa, MM, Mostafa, DK, Ghazy, AA, Boulos, LM, Younis, LK, 2016: Anti-arthritic activity of Schistosoma mansoni and Trichinella spiralis derived-antigens in adjuvant arthritis in rats: role of FOXP3+ Treg cells. PLoS One11:e165916.

El-Malky, M, Nabih, N, Heder, M, Saudy, N, El-Mahdy, M, 2011: Helminth infections: Therapeutic potential in autoimmune disorders. Parasite Immunol. 33, 11:589-93.

Erpenbeck, VJ, Hohlfeld, JM, Petschallies, J, Eklund, E, Peterson, CGB, et al, 2003: Local release of eosinophil peroxidase following segmental allergen provocation in asthma. Clin. Exp. Aller. 33, 3:331-6.

Fabre, MV, Beiting, DP, Bliss, SK, Appleton, JA, 2009: Immunity to Trichinella spiralis muscle infection. Vet Parasitol. 159, 3-4:245-8.

Fahy, JV, 2015: Type 2 inflammation in asthma-present in most, absent in many. Nat. Rev. Immunol. 15, 1:57-65.

Finlay, CM, Stefanska, AM, Coleman, MM, Jahns, H, Cassidy, JP, et al, 2017: Secreted products of Fasciola hepatica inhibit the induction of T cell responses that mediate allergy. Parasite Immunol. 39, 10:e12460.

Fleming, JO, Isaak, A, Lee, JE, Luzzio, CC, Carrithers, MD, et al, 2011: Probiotic helminth administration in relapsing-remitting multiple sclerosis: A phase 1 study. Mult Scler. 17, 6: 743-54.

Fontenot, JD, Gavin, MA, Rudensky, AY, 2003: Foxp3 programs the development and function of CD4+ CD25+ regulatory T cells. Nat. Immunol. 4, 4: 330-6.

Gou, HF, Chen, XC, Zhu, J, Jiang, M, Yang, Y, et al, 2011: Expressions of COX-2 \& VEGF$\mathrm{C}$ in gastric cancer: correlations with lymphangiogenesis and prognostic implications. J. Exp. Clin. Cancer Res. 30, 1:14-8.

Gruden-Movsesijan, A, Ilic, N, Mostarica-Stojkovic, M, Stosic-Grujicic, S, Milic, M, et al, 2010: Mechanisms of modulation of experimental autoimmune encephalomyelitis by chronic Trichinella spiralis infection in Dark Agouti rats. Parasite Immunol. 32:450-9.

Guo, K, Sun, X, Gu, Y, Wang, Z, Huang, J, et al, 2016: Trichinella spiralis paramyosin activates mouse bone marrow-derived dendritic cells and induces regulatory T cells. Parasit. Vect. 9, 1:1-11.

Hawrylowicz, CM, O'garra, A, 2005: Potential role of interleukin-10-secreting regulatory $\mathrm{T}$ cells in allergy and asthma. Nat. Rev. Immunol. 5, 4:271-83.

Ilic, N, Gruden-Movsesijan, A, Sofronic-Milosavljevic, L, 2012: Trichinella spiralis: shaping the immune response. Immunol. Res. 52, 1-2: 111-9.

Khattri, R, Cox, T, Yasayko, SA, Ramsdell, F, 2003: An essential role for Scurfin in CD4+ CD25+ T regulatory cells. Nat Immunol. 4, 4: 337-42.

Klein, L, Khazaie, K, Von Boehmer, H, 2003: In vivo dynamics of antigen-specific regulatory $\mathrm{T}$ cells not predicted from behavior in vitro. Proc. Natl. Acad. Sci. 100, 15: 8886-91.

Lambrecht, BN, Hammad, H, 2013: Asthma: The importance of dysregulated barrier immunity. Eur. J. Immunol. 43, 12:3125-37.

Ling, EM, Smith, T, Nguyen, XD, Pridgeon, C, Dallman, M, et al, 2004: Relation of CD4+ $\mathrm{CD} 25+$ regulatory $\mathrm{T}$-cell suppression of allergen-driven T-cell activation to atopic status and expression of allergic disease. Lancet 363, 9409: 608-15.

Loukas, A, Hotez, PJ, Diemert, D, Yazdanbakhsh, M, McCarthy, JS, et al, 2016: Hookworm infection. Nat. Rev. Dis. Primers 2, 1:1-18.

Mangan, NE, van Rooijen, N, McKenzie, AN, Fallon, PG, 2006: Helminth-modified pulmonary immune response protects mice from aller- 
gen-induced airway hyperresponsiveness. J. Immunol. 176, 1:138-47.

Marinho, FV, Alves, CC, de Souza, SC, da SiIva, CMG, Cassali, GD, et al, 2016: Schistosoma mansoni tegument (Smteg) induces IL-10 and modulates experimental airway inflammation. PLoS One 11, 7:e0160118.

McSorley, HJ, Blair, NF, Smith, KA, McKenzie, AN, Maizels, RM, 2014: Blockade of IL-33 release and suppression of type 2 innate lymphoid cell responses by helminth secreted products in airway allergy. Mucosal Immunol. 7, 5:106878.

Obieglo, K, Schuijs, MJ, Ozir-Fazalalikhan, A, Otto, F, van Wijck, Y, et al, 2018: Isolated Schistosoma mansoni eggs prevent allergic airway inflammation. Parasit. Immunol. 40, 10: e12579.

Park, HK, Cho, MK, Choi, SH, Kim, YS, Yu, HS, 2011: Trichinella spiralis: infection reduces airway allergic inflammation in mice. Exp. Parasitol. 127, 2: 539-44.

Peters, TE, Fritz, GK, 2011: Psychological considerations of the child with asthma. Pediatr. Clin. North Am. 58, 4:921-35.

Saunders, KA, Raine, T, Cooke, A, Lawrence, CE, 2007: Inhibition of autoimmune type 1 diabetes by gastrointestinal helminth infection. Infect. Immun. 75, 1:397-407.

Shamri, R, Xenakis, JJ, Spencer, LA, 2011: Eosinophils in innate immunity: an evolving story. Cell Tissue Res. 343, 1:57-83.

Shi, HZ, Li, S, Xie, ZF, Qin, XJ, Qin, X, et al, 2004: Regulatory CD4+ CD25+ T lymphocytes in peripheral blood from patients with atopic asthma. Clin Immunol. 113, 2:172-8.

Smits, HH, Hammad, H, van Nimwegen, M, Soullie, T, Willart, MA, et al, 2007: Protective effect of Schistosoma mansoni infection on allergic airway inflammation depends on the intensity and chronicity of infection. J. Aller. Clin. Immunol. 120, 4:932-40.

Sofronic-Milosavljevic, L, Ilic, N, Pinelli, E, Gruden-Movsesijan, A, 2015: Secretory products of Trichinella spiralis muscle larvae and immunomodulation: implication for autoimmune diseases, allergies, and malignancies. J. Immunol. Res. 15:523875.

Summers, RW, Elliot, DE, Urban, JrJF, 2005: Trichuris suis therapy in Crohn's disease. Gut 5: 15591509.

Suri-Payer, E, Cantor, H, 2001: Differential cytokine requirements for regulation of autoimmune gastritis and colitis by CD4+ CD25+ T cells. J. Autoimmun.16, 2:115-23.

Tang, Q, Bluestone, JA, 2008: The Foxp3+ regulatory $\mathrm{T}$ cell: a jack of all trades, master of regulation. Nat. Immunol. 9, 3:239-44.

Theofilopoulos, AN, Kono, DH, Baccala, R, 2017: The multiple pathways to autoimmunity. Nat. Immunol. 18, 7:716-9.

Trujillo-Vargas, CM, Mayer, KD, Bickert, T, Palmetshofer, A, Grunewald, S, et al, 2005: Vaccinations with T-helper type 1 directing adjuvants have different suppressive effects on the development of allergen-induced T-helper type 2 responses. Clin. Exp. Aller. 35, 8:1003-13.

Yang, X, Yang, Y, Wang, Y, Zhan, B, Gu, Y, et al, 2014: Excretory/secretory products from Trichinella spiralis adult worms ameliorate DSS -induced colitis in mice. PLoS One 9, 5: e96454.

Zwiernik, J, Arłukowicz, T, Zwiernik, B, Matyskieła, T, Dargiewicz, M, et al, 2019: Therapeutic applicability of helminths in autoimmune diseases-literature overview. Prz. Gastroenterol. $14,3: 168-72$.

\section{Legends of figures}

Fig 1. Representative photomicrographs of histopathological findings in lung sections, A- induced asthma group showed marked peribronchial and perivascular inflammatory cell infiltration mainly eosinophils, thickening of bronchial walls and congested adjacent small blood vessels (yellow arrows), B- saline control group showed normal brochial architecture, clear alveoli with intact lumen and no inflammatory cell infiltration, C-low dose preventive group showed scattered areas of mild peribronchial and perivascular inflammatory cell infiltration (yellow arrows), D- high dose preventive group showing mild peribronchial and perivascular inflammatory cell infiltration, nearly similar to low dose preventive group, E- low dose therapeutic group showed moderate peribronchial and perivascular inflammatory cell infiltration, \&F- high dose therapeutic group showed moderate peribronchial and perivascular inflammatory cell infiltration $(\mathrm{H} \& \mathrm{E} \times 100)$ Fig 2: Representative photograph of immunohistochemical stained lung sections showing FOXP3 ${ }^{+} \mathrm{CD}^{+}{ }^{\mathrm{T}}$ cells expression in inflammatory cell infiltrate (yellow arrows). A- induced asthma group showed weak expression, B- saline control group showed negative expression, Clow dose preventive group showed strong expression, D- high dose preventive group showed strong expression, E- low dose therapeutic group showed moderate expression, \&F- high dose therapeutic group showed moderate expression (Immunoperoxidase $\times 400$ ) 


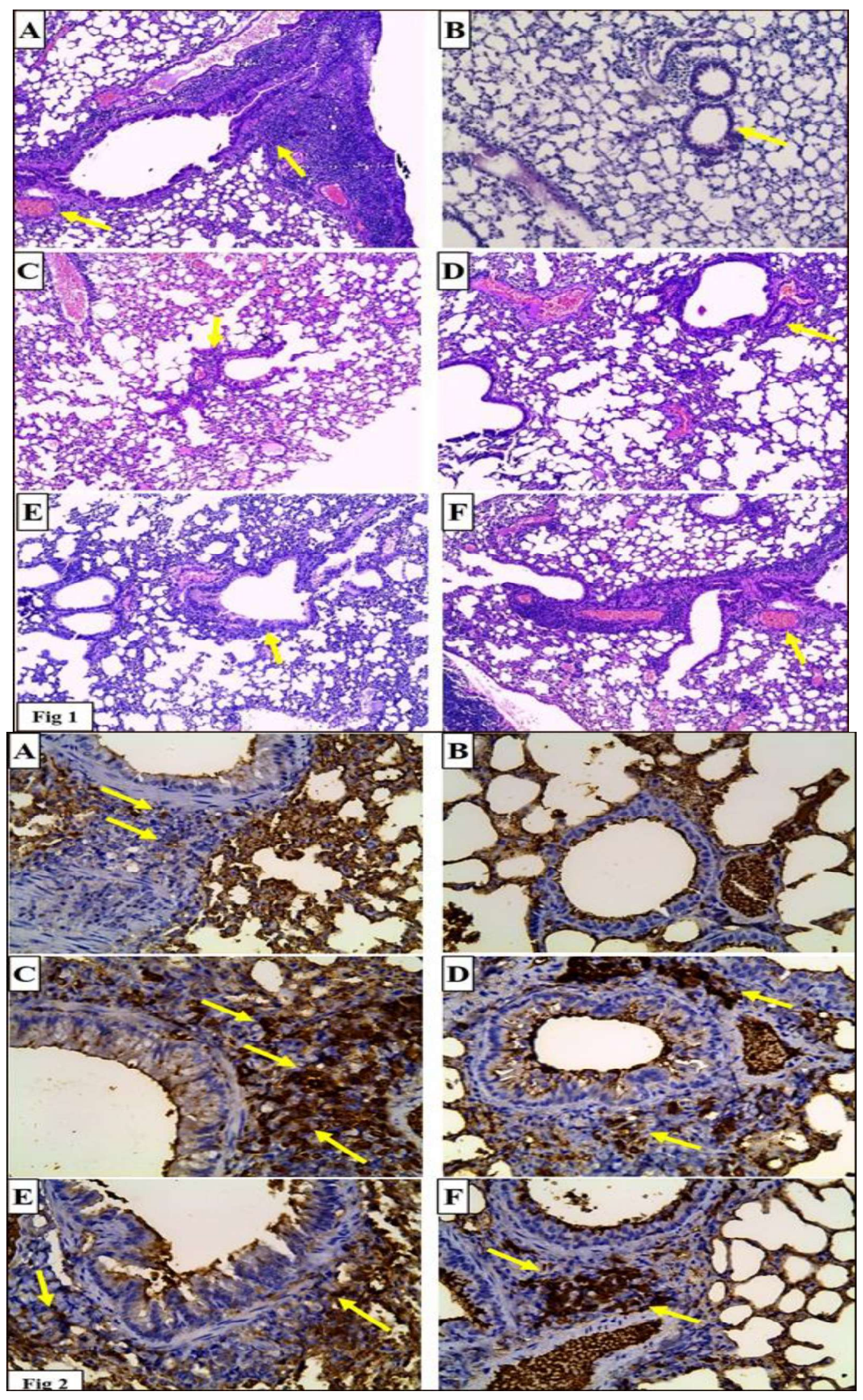

